Tropical Journal of Pharmaceutical Research March 2016; 15 (3): 631-638

ISSN: $1596-5996$ (print); 1596-9827 (electronic)

(C) Pharmacotherapy Group, Faculty of Pharmacy, University of Benin, Benin City, 300001 Nigeria.

All rights reserved.

Available online at http://www.tjpr.org

Original Research Article

http://dx.doi.org/10.4314/tjpr.v15i3.27

\title{
Pharmacokinetic Interaction between Magnolol and Piperine in Rats
}

\author{
Xiao-Ying Chen ${ }^{1}$, Guang-Hua Yang ${ }^{1}$, Cai-LanLi ${ }^{1}$, Xiu-Ting $\mathrm{Yu}^{2}$, Xiu-Fen Wang ${ }^{1}$, \\ Yi-Feng Zheng ${ }^{1}$, Jian-Hui $\mathrm{Xie}^{3}$, Xiao-PingLai ${ }^{1,5}$, Zi-Ren $\mathrm{Su}^{1,5}$, Yong-Zhuo \\ Liang $^{1,4 \star}$ and Ji Lin ${ }^{1}$ \\ ${ }^{1}$ College of Chinese Medicines, Guangzhou University of Chinese Medicine, Guangzhou 510006, ${ }^{2}$ The First Affiliated Hospital \\ of Chinese Medicine, Guangzhou University of Chinese Medicine, Guangzhou 510405, ${ }^{3}$ Guangdong Provincial Key Laboratory \\ of Clinical Research on Traditional Chinese Medicine Syndrome. The Second Affiliated Hospital, Guangzhou University of \\ Chinese Medicine, Guangzhou, 510006, ${ }^{4}$ Patent Examination Cooperation Center of the Patent Office, SIPO, Guangdong, \\ Guangzhou, 510530, ${ }^{5}$ Dongguan Mathematical Engineering Academy of Chinese Medicine, Guangzhou University of Chinese \\ Medicine, Dongguan, 523808, Peoples Republic of China
}

*For correspondence: Email: liangyongzhuo@163.com, linji88@gzucm.edu.cn; Tel: +86-20-39358517; Fax: +86-20-39358390

\begin{abstract}
Purpose: To investigate the pharmacokinetic mechanism of interaction between magnolol and piperine when co-administered to rats.

Methods: The rats were divided into five groups as follows: magnolol group (625 mg/kg); low dose of piperine group (20 mg/kg); high dose of piperine group (40 mg/kg); low dose of piperine + magnolol group; or high dose of piperine + magnolol group. Plasma samples were collected at regular time intervals after administration of a single dose of magnolol (625 mg/kg, p.o.) alone or piperine (20 or 40 $\mathrm{mg} / \mathrm{kg}$, p.o.) in the presence or absence of magnolol (625 $\mathrm{mg} / \mathrm{kg}$, p.o.). The concentrations of magnolol and piperine in plasma were measured by a validated high performance liquid chromatography (HPLC) method.

Results: Compared with control, the groups given magnolol alone, concomitant administration of piperine and magnolol resulted in significant decrease $(p<0.01)$ in the AUC and $C_{\max }$ of magnolol. Interestingly, compared with administration of piperine alone $(20 \mathrm{mg} / \mathrm{kg})$, co-administration with magnolol did not significantly $(p>0.05)$ alter the pharmacokinetic parameters of piperine. However, at high dose $(40 \mathrm{mg} / \mathrm{kg})$ of piperine, $C_{\max }$ of piperine significantly decreased from $4.30 \pm 1.47$ to $2.50 \pm$ $0.78 \mu \mathrm{g} / \mathrm{mL}(\mathrm{p}<0.05)$.

Conclusion: Co-administration of magnolol and piperine decreases plasma concentration of either drug in rats, suggesting that concurrent use of magnolol with piperine or piperine-containing diets would require close monitoring for potential interactions.
\end{abstract}

Keywords: Magnolol, Piperine, Pharmacokinetic interaction, Co-administration

Tropical Journal of Pharmaceutical Research is indexed by Science Citation Index (SciSearch), Scopus, International Pharmaceutical Abstract, Chemical Abstracts, Embase, Index Copernicus, EBSCO, African Index Medicus, JournalSeek, Journal Citation Reports/Science Edition, Directory of Open Access Journals (DOAJ), African Journal Online, Bioline International, Open-J-Gate and Pharmacy Abstracts

\section{INTRODUCTION}

Magnolol a substrate for P-glycoprotein (P-gp), shown in Figure 1a, is one of the major compounds contained in the bark of Magnolia officinalis, which has been widely prescribed for the treatment of gastrointestinal diseases [1]. Various studies have shown that magnolol has a variety of pharmacological activities such as cardio-protection, anti-inflammation, antidepression, anti-carcinogenic and anti-bacterial effect [2-4]. However, the oral bioavailability of 
magnolol, is reported to be only $5 \%$ due to extensive first-pass metabolism and low absorption [5]. Efflux transporters such as P-gp are critical functional proteins in drug metabolism and transport, and have been shown to limit oral drug absorption and tissue distribution [6]. It is speculated that the concomitant use with compounds that influence the P-gp may change its pharmacokinetics.

Piperine (1-peperoyl peperidine, Figure 1b), a major active ingredient of black pepper (Piper nigrum Linn.) and long pepper (Piper longum Linn.), has been shown to have fundamental effects on P-gp and many enzyme systems, leading to biotransformative effects including detoxification and enhancement of the absorption and bioavailability of herbal and conventional drugs. At present, piperine has been found to increase the plasma concentrations of various structurally and therapeutically diverse drugs, such as theophylline, phenytoin, rifampin, and propranolol [7], possibly due to the inhibition of metabolic pathways and /or P-gp-mediated drug efflux.

In traditional Chinese medicine, magnolia bark was commonly prescribed with long pepper in Chinese formula such as "Houpu-biba Wan" in the therapy of gastrointestinal disorders. Due to the common use of magnolol and piperine in the digestive system as dietary supplements or in medicinal forms, the prediction of their possible pharmacokinetic interaction would help to provide beneficial information and facilitate their safe application. Therefore, the purpose of this study was to investigate whether and how peperine affected the pharmacokinetics of magnolol in rats after oral administration at different dosages, and estimate their concentrations in plasma by RP-HPLC method.
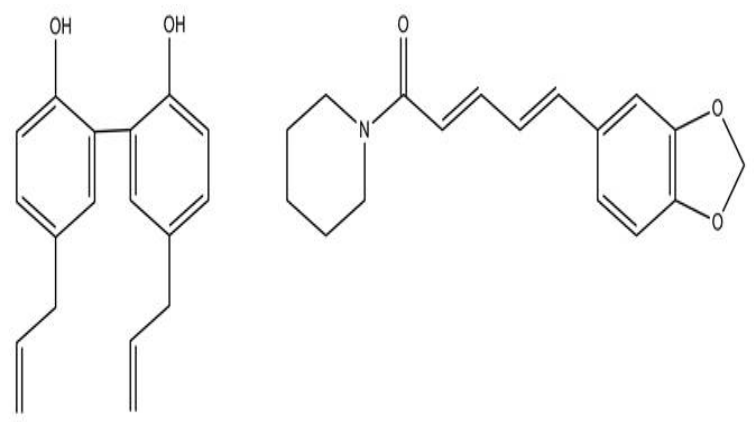

(a)

\section{EXPERIMENTAL}

\section{Chemicals and reagents}

Piperine with purity $>99 \%$ was purchased from Xian Kaicheng Biological Technology Co., Ltd, Xian, China. Magnolol with purity $>99 \%$ was obtained from Guangzhou Hechengsanxian biological technology Co., Ltd, Guangzhou, China. Osthole $\left(\mathrm{C}_{15} \mathrm{H}_{16} \mathrm{O}_{3}\right)$, used as internal standard (IS), was obtained from National Institute for the Control of Pharmaceutical and Biological Products. HPLC-grade methanol was purchased from Merck KGaA (Darmstadt, Germany), and acetic acid from Guangdong Guanghua Chemical Factory Co., Ltd. (Guangdong, China). Ultrapure water was prepared using a Milli-Q gradient water purification system (Millipore, Bedford, MA, USA). All other regents and chemicals used in this study were of analytical grade.

\section{Instrumentation and conditions}

Shimadzu HPLC system (Kyoto, Japan) consisting of pump (LC-20AD), UV detector (SPD-20A) and LC solution chromatographic workstation was used for all analyses. The chromatographic resolutions of piperine and magnolol were carried out on a Diamonsil C18 column (particle size, $5 \mu \mathrm{m}, 250 \times 4.6 \mathrm{~mm}$, Dikma, China) with the isocratic mobile phase consisting of methanol and $0.1 \%$ acetic acid in water $(78: 22, \mathrm{v} / \mathrm{v})$ at a flow rate of $1.0 \mathrm{~mL} / \mathrm{min}$. An aliquot of $10 \mu \mathrm{L}$ blood sample was injected for HPLC analysis, and the UV detection wavelengths were set at $294 \mathrm{~nm}$ and $340 \mathrm{~nm}$ for magnolol and piperine, respectively.

\section{Animals}

Male Sprague-Dawley rats $(200 \pm 20 \mathrm{~g})$ were purchased from the Laboratory Animal Center, Guangzhou University of Chinese Medicine (Guangzhou, China). All experimental protocols involving animals and their care were approved (ref. no. SYXK (YUE) 2008-0085) by the Animal Experimental Ethics Committee of Guangzhou University of Chinese Medicine (Guangzhou, China), and the experimental protocols followed the "Guide for the Care and Use of Laboratory Animals" [8].

Rats housed in the standard rat cages were kept at ambient temperature with a relative humidity of $50 \pm 10 \%$ and $12 \mathrm{~h} \mathrm{light/dark} \mathrm{cycle.} \mathrm{The} \mathrm{animals}$ were used for studies after one week acclimatization with free access to water and standard rat chow.
Figure 1: Chemical structures of magnolol (a) and piperine (b) 


\section{Experimental design and pharmacokinetic studies}

All rats were fasted overnight but supplied with water ad libitum prior to the pharmacokinetic investigation. Rats were randomly divided into the following five groups $(n=6)$ : group 1: magnolol $(625 \mathrm{mg} / \mathrm{kg})$, group 2: low dose of piperine $(20 \mathrm{mg} / \mathrm{kg})$, group 3: high dose of piperine $(40 \mathrm{mg} / \mathrm{kg})$, group 4: low dose of piperine $(20 \mathrm{mg} / \mathrm{kg})+$ magnolol $(625 \mathrm{mg} / \mathrm{kg})$, and group 5: high dose of piperine $(40 \mathrm{mg} / \mathrm{kg})+$ magnolol $(625 \mathrm{mg} / \mathrm{kg})$.

Both magnolol and piperine were prepared as suspensions in $0.5 \%$ carboxymethyl cellulose sodium salt (CMC-Na) aqueous solution just before each experiment. The dose levels of piperine have been selected based on our previous pharmacokinetic studies [9]. The dose of magnolol was chosen based on the clinical use and our preliminary experiment.

Blood samples were collected from the suborbital vein into heparinized Eppendorf microtubes, before administration and at $0.25,0.5,0.75,1$, $1.5,2,4,6,8,12$ and $24 \mathrm{~h}$ after administration. After collection, the plasma samples were immediately separated by centrifugation at $10,000 \mathrm{rpm}$ for $10 \mathrm{~min}$ and stored at $-20{ }^{\circ} \mathrm{C}$ for subsequent analysis.

\section{Preparation of plasma samples}

To a $100 \mu \mathrm{L}$ aliquot of blood plasma sample in a $2 \mathrm{~mL}$ Eppendorf microtube, $50 \mu \mathrm{L}$ of internal standard $(9.48 \mu \mathrm{g} / \mathrm{mL})$ was added. The samples were vortexed for 2 min and $450 \mu \mathrm{L}$ of methanol was added. The mixture was vortex-mixed for 3 min. After centrifugation at 10,000 rpm for $5 \mathrm{~min}$, the supernatant was separated and evaporated. The resulting dried residue was reconstituted in $200 \mu \mathrm{L}$ of methanol and then centrifuged at 2, $000 \mathrm{rpm}$ for $10 \mathrm{~min}$. The supernatant was isolated for HPLC analysis.

\section{Preparation of standard solution}

Individual stock solutions of magnolol (100 $\mu \mathrm{g} / \mathrm{mL})$ and piperine $(100 \mu \mathrm{g} / \mathrm{mL})$ were prepared in methanol. A stock solution of IS was prepared by dissolving osthole in methanol to a final concentration of $9.48 \mu \mathrm{g} / \mathrm{mL}$. A serious of working solutions were obtained by further diluting the stock solutions. Calibration standards were prepared by spiking the appropriate amounts of standard solutions into blank plasma to obtain final concentrations levels of $0.8,1.0$, 2.5, 5.0, 10.0, $20.0 \mu \mathrm{g} / \mathrm{mL}$ and $0.1,0.5,1.0,2.5$, $5.0,10.0 \mu \mathrm{g} / \mathrm{mLfor}$ magnolol and piperine respectively. The quality control (QC) samples were similarly prepared at concentrations of 0.8 , $2.5,10 \mu \mathrm{g} / \mathrm{mL}$ and $0.5,2.5,5.0 \mu \mathrm{g} / \mathrm{mL}$ for low, medium and high concentration QC samples magnolol and piperine, respectively. All working solutions were stored at $-4^{\circ} \mathrm{C}$.

\section{Method validation}

The method was validated for specificity, linearity, accuracy, precision, recovery and stability, according to the principles of the US Food and Drug Administration (2001) industry guidance for bioanalytical method validation.

\section{Specificity}

The specificity was evaluated by comparing chromatograms of blank plasma and plasma spiked with the standard solutions.

\section{Linearity of calibration curves and lower limits of quantification (LLOQ)}

The calibration curves of magnolol and piperine were performed with six concentrations. Peakarea ratios of the analyte to the IS were calculated and the calibration curves were established by fitting the ratio to the corresponding concentrations using regression analysis with $1 / X^{2}$ weighting. LLOQ was defined as the lowest concentration on the calibration curve at which the signal-to-noise ratio was above 10 with an acceptable accuracy within \pm $10 \%$ and the precision below $15 \%$.

\section{Accuracy and precision}

Intra- and inter-day precisions were determined by assessing the measured results of the QC samples at low, medium, and high concentrations. Precision was evaluated as the relative standard deviation (RSD), while accuracy (\%) was evaluated by the percentage difference between the mean measured concentrations and the spiked concentrations, expressed as the relative error (RE).

\section{Recovery}

Extraction recoveries were determined by comparing the ratio of analyte peak areas of the extracted QC samples with those of un-extracted standard solutions at the same nominal concentrations. The matrix effects were measured by comparing the peak areas of blank plasma extracts spikes with analytes with those of pure standard solution containing equivalent amounts of the analytes. 


\section{Stability}

Stability was checked by comparing the measured results with those of the freshly prepared samples of the same concentration under different storage conditions: short-term stability at room temperature for $4 \mathrm{~h}$; long-term stability at $-20^{\circ} \mathrm{C}$ for 7 days; after three freezethaw cycles $[9,10]$.

\section{Pharmacokinetic studies}

Pharmacokinetic analysis was performed based on a non-compartmental description of the data obtained. Drug and Statistics software (version 3.1.5, BioGuider Co., Shanghai, China) was used to calculate the model-independent parameters, such as the area under plasma concentrationtime curve (AUC), volume of distribution $\left(V_{d}\right)$, clearance $(C L)$ and half-life $\left(t_{1 / 2}\right)$. In addition, the maximum plasma concentration $\left(\mathrm{C}_{\max }\right)$ and the time to reach the maximum plasma concentration $\left(T_{\text {max }}\right)$ were obtained from the plasma concentration-time data.

\section{Statistical analysis}

All means were presented with their standard deviation (SD). Comparisons of the pharmacokinetic parameters were analyzed by the two-tailed unpaired Student's t-test, and $p<$ 0.05 was considered statistically significant (SPSS statistical software package, version 17.0, SPSS Inc., Chicago, IL, USA).

\section{RESULTS}

\section{HPLC analysis}

To obtain a rapid and simple HPLC-UV method for simultaneous determination of magnolol and piperine in the rat plasma, the chromatographic conditions were optimized and validated. The representative chromatograms of plasma spiked with the standard solutions were shown in Figure 2. The retention time for magnolol, piperine and internal standard (IS) were approximately 20.1, 10.5 and $12.8 \mathrm{~min}$, respectively. Under the optimized conditions, no significant endogenous interference was observed.

\section{Method validation}

The calibration curve from magnolol was found to be linear over the concentration range of 0.8 to $20 \mu \mathrm{g} / \mathrm{mL}$ in rat plasma with the linear regression equation $Y=0.0775 X-0.0295\left(R^{2}=0.9998\right)$. The lower limit of quantification (LLOQ) was 0.8 $\mu \mathrm{g} / \mathrm{mL}$. The intra- and inter-day precision of magnolol was $<10 \%$, and accuracy ranged from -3.3 to $8.9 \%$.

The standard curve developed to quantify the piperine concentration in the rat blood was of good linearity $\left(R^{2}=0.9988\right)$ over the concentration range of 0.1 to $10 \mu \mathrm{g} / \mathrm{mL}$. The intra- and inter-day precision of piperine was < $12 \%$, and the accuracy was between -4.6 and $9.3 \%$, respectively.

The mean extraction recoveries at three QC levels were $91.33 \pm 5.11,98.07 \pm 4.95$ and 94.91 $\pm 4.02 \%$ for magnolol, and $90.14 \pm 4.57,96.16 \pm$ 4.21 and $93.66 \pm 3.96 \%$ for piperine, respectively. No significant matrix effect for magnolol, piperine and IS was observed, which indicated that the co-eluting substance did not influence the ionization of the analytes and IS. No significant changes in serum concentrations of magnolol and piperine were detected after three freezing and thawing cycles, as well as at room temperature for $4 \mathrm{~h}$ and at $-20{ }^{\circ} \mathrm{C}$ for 7 days, respectively.
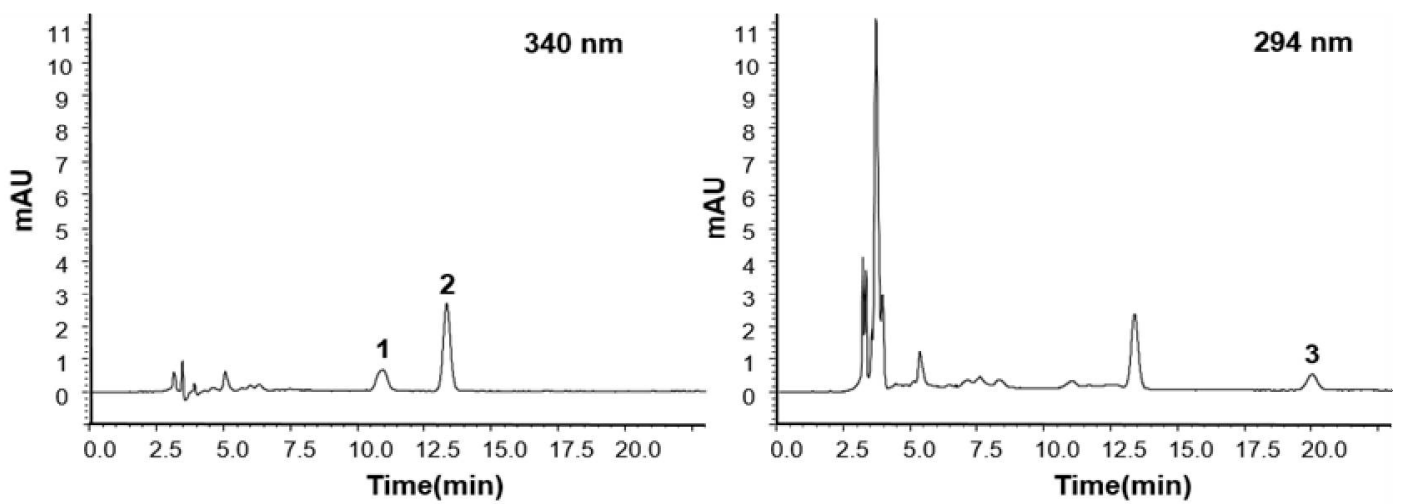

Figure 2: Typical chromatograms of rat plasma sample after simultaneous oral administration of magnolol and piperine 
The results indicated that the proposed method was validated to guarantee a reliable determination of magnolol and piperine in rat plasma and was applicable to the pharmacokinetic study on magnolol and piperine in rat plasma.

\section{Effect of piperine on the oral pharmacokine- tics of magnolol}

The mean plasma concentration-time plots of magnolol following oral administration in the presence or absence of piperine are depicted in Figure 3 , and the mean pharmacokinetic parameters of magnolol are summarized in Table 1. Compared with the control group given magnolol alone, the AUC of magnolol was significantly decreased from $105.42 \pm 21.70$ $\mu \mathrm{g} / \mathrm{mL}^{*} \mathrm{~h}$ in the control group to $36.72 \pm 12.62$ and $39.36 \pm 17.67 \mu \mathrm{g} / \mathrm{mL}^{*} \mathrm{~h}(p<0.01)$ for 20 and $40 \mathrm{mg} / \mathrm{kg}$ piperine treatment group, respectively. Similarly, $\mathrm{C}_{\max }$ of magnolol significantly declined to 58.91 and $71.10 \%$ (both $p<0.01$ ) via the concomitant use of 20 and $40 \mathrm{mg} / \mathrm{kg}$ piperine, respectively, as compared with the control group. In contrast, $\mathrm{CL}$ of magnolol was significantly increased from $5.98 \pm 1.67 \mathrm{~L} / \mathrm{h} / \mathrm{kg}$ in the control group to $17.62 \pm 4.58(p<0.01)$ and $17.39 \pm$ $6.18 \mathrm{~L} / \mathrm{h} / \mathrm{kg}(p<0.05)$ in the 20 and $40 \mathrm{mg} / \mathrm{kg}$ piperine treatment group, respectively. Meanwhile, $t_{1 / 2}$ of magnolol was similar in the presence or absence of piperine. When compared with control group, magnolol blood concentrations of the rats pre-treated with 20 $\mathrm{mg} / \mathrm{kg}$ piperine, however, were not significantly different from those pre-treated with $40 \mathrm{mg} / \mathrm{kg}$ piperine.

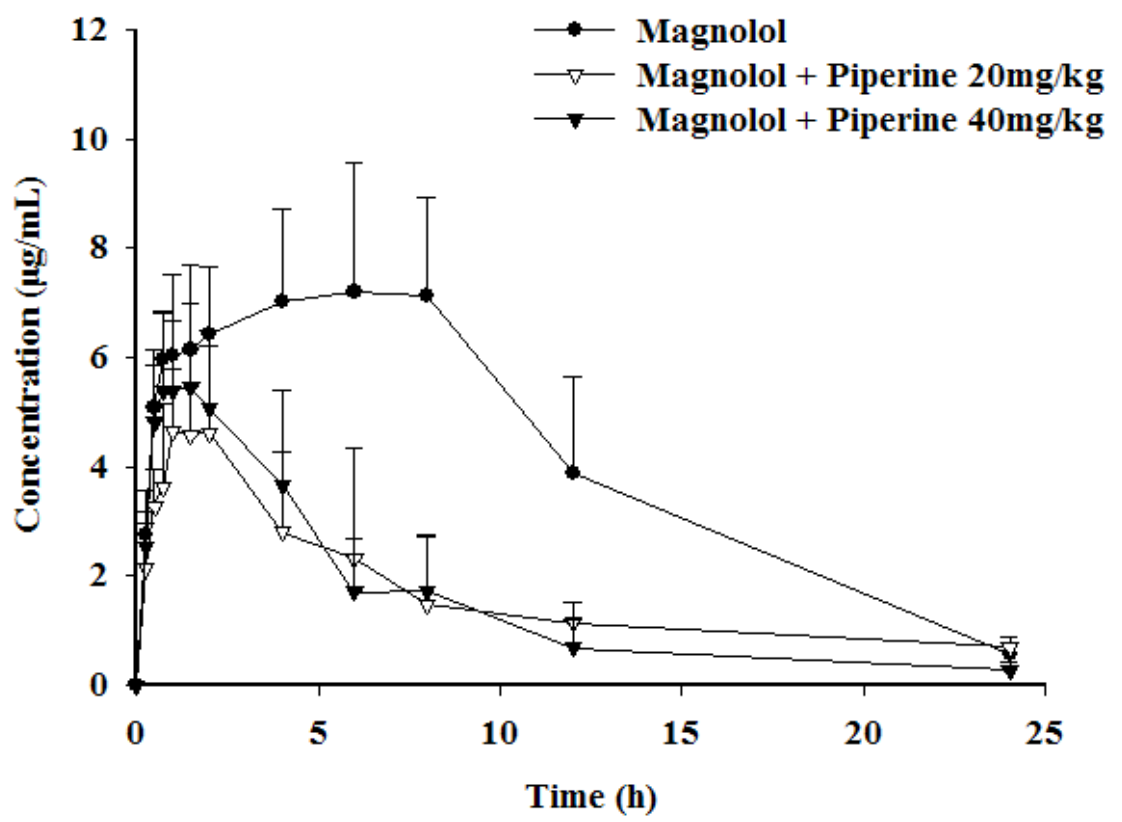

Figure 3: Plasma concentration-time profiles of magnolol after oral administration of magnolol to rats in the presence and absence of piperine. The data are expressed as mean $\pm \mathrm{SD}, n=6$. (•) control (magnolol alone); $(\Delta)$ combined with $20 \mathrm{mg} / \mathrm{kg}$ of piperine; $(\boldsymbol{\nabla})$ combined with $40 \mathrm{mg} / \mathrm{kg}$ of piperine

Table 1: Pharmacokinetic parameters for magnolol in rats after oral administration in the presence and absence of piperine (mean $\pm \mathrm{SD}, n=6)$

\begin{tabular}{|c|c|c|c|}
\hline \multirow{2}{*}{ Parameter } & \multirow{2}{*}{ Magnolol alone } & \multicolumn{2}{|c|}{ With piperine } \\
\hline & & $20 \mathrm{mg} / \mathrm{kg}$ & $40 \mathrm{mg} / \mathrm{kg}$ \\
\hline $\mathrm{AUC}_{0-\mathrm{t}}\left(\mu \mathrm{g} / \mathrm{mL}^{*} \mathrm{~h}\right)$ & $100.74 \pm 19.11$ & $32.92 \pm 11.13^{\star *}$ & $36.77 \pm 14.45^{\star \star}$ \\
\hline $\mathrm{AUC}_{0-\infty}\left(\mu \mathrm{g} / \mathrm{mL}^{*} \mathrm{~h}\right)$ & $105.42 \pm 21.70$ & $36.72 \pm 12.62^{\star *}$ & $39.36 \pm 17.67^{\star \star}$ \\
\hline$C_{\max }(\mu \mathrm{g} / \mathrm{mL})$ & $9.03 \pm 1.26$ & $5.32 \pm 1.41^{* *}$ & $6.42 \pm 0.80^{\star *}$ \\
\hline$T_{\max }(\mathrm{h})$ & $5.67 \pm 1.97$ & $1.75 \pm 0.42^{* *}$ & $1.15 \pm 0.60^{* *}$ \\
\hline$V_{d}(\mathrm{~L} / \mathrm{kg})$ & $27.14 \pm 15.67$ & $59.70 \pm 18.34^{\star *}$ & $62.129 \pm 28.08 *$ \\
\hline$C L(\mathrm{~L} / \mathrm{h} / \mathrm{kg})$ & $5.98 \pm 1.67$ & $17.62 \pm 4.58^{\star \star}$ & $17.39 \pm 6.18^{*}$ \\
\hline$t_{1 / 2}(\mathrm{~h})$ & $4.10 \pm 2.19$ & $2.99 \pm 1.60$ & $1.94 \pm 0.42$ \\
\hline
\end{tabular}

Note: Asterisks indicate significant differences: ${ }^{*} p<0.05$ and ${ }^{* *} p<0.01$ versus control group given magnolol alone 
Effect of magnolol on oral pharmacokinetics of piperine

The mean plasma concentration-time profiles of piperine $(20$ and $40 \mathrm{mg} / \mathrm{kg}$ ) administered alone or in combination with $625 \mathrm{mg} / \mathrm{kg}$ magnolol are shown in Figures 4 and 5, and the pharmacokinetic parameters were summarized in Table 2. As shown in Table 2, co-administration of magnolol did not significantly alter the pharmacokinetic parameters of piperine when compared with the administration of piperine alone $(20 \mathrm{mg} / \mathrm{kg})$. However, at high dose of piperine $(40 \mathrm{mg} / \mathrm{kg})$, the $C_{\max }$ of piperine was significantly decreased from $4.30 \pm 1.47 \mu \mathrm{g} / \mathrm{mL}$ to $2.50 \pm 0.78 \mu \mathrm{g} / \mathrm{mL}(p<0.05)$. Nevertheless, there was no significant difference in the AUC and $t_{1 / 2}$ of piperine in the plasma when piperine was administered alone or in combination with magnolol.

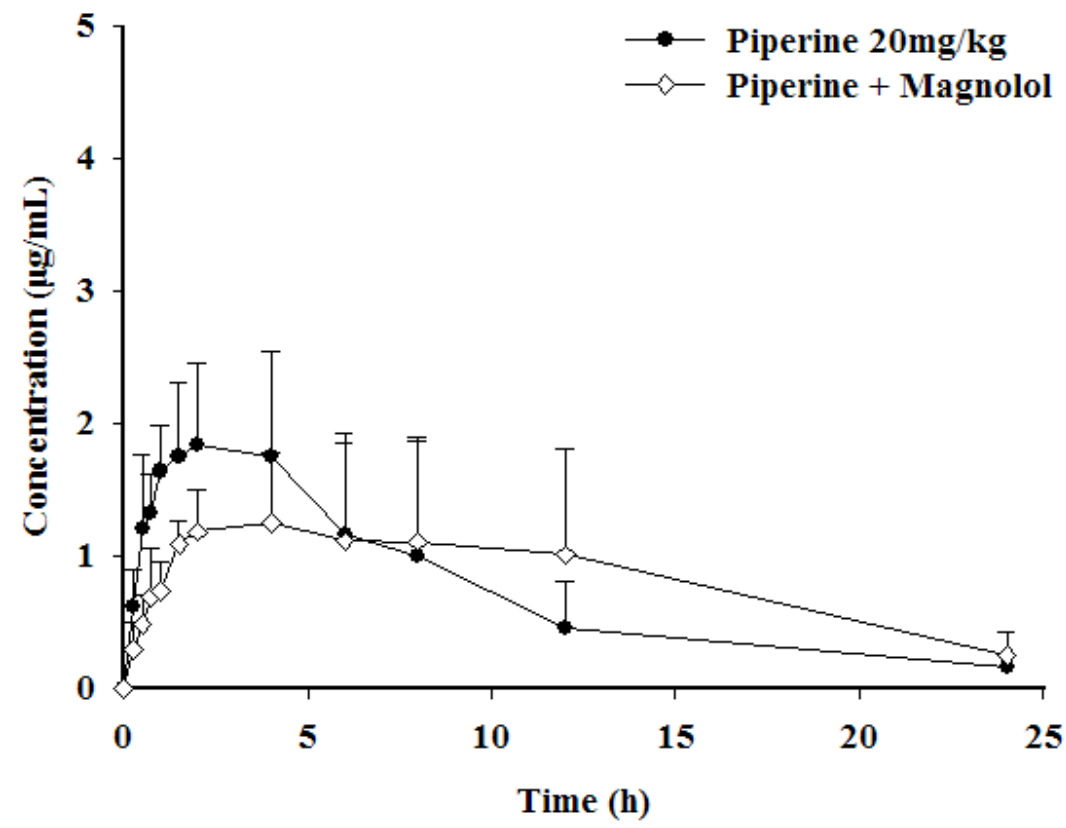

Figure 4: Plasma concentration-time profiles of piperine after oral administration of $20 \mathrm{mg} / \mathrm{kg}$ of piperine to rats in the presence and absence of magnolol. The data are expressed as mean $\pm \mathrm{SD},(n=6)$. $(\bullet)$ piperine with CMC; $(\diamond)$ piperine combined with magnolol

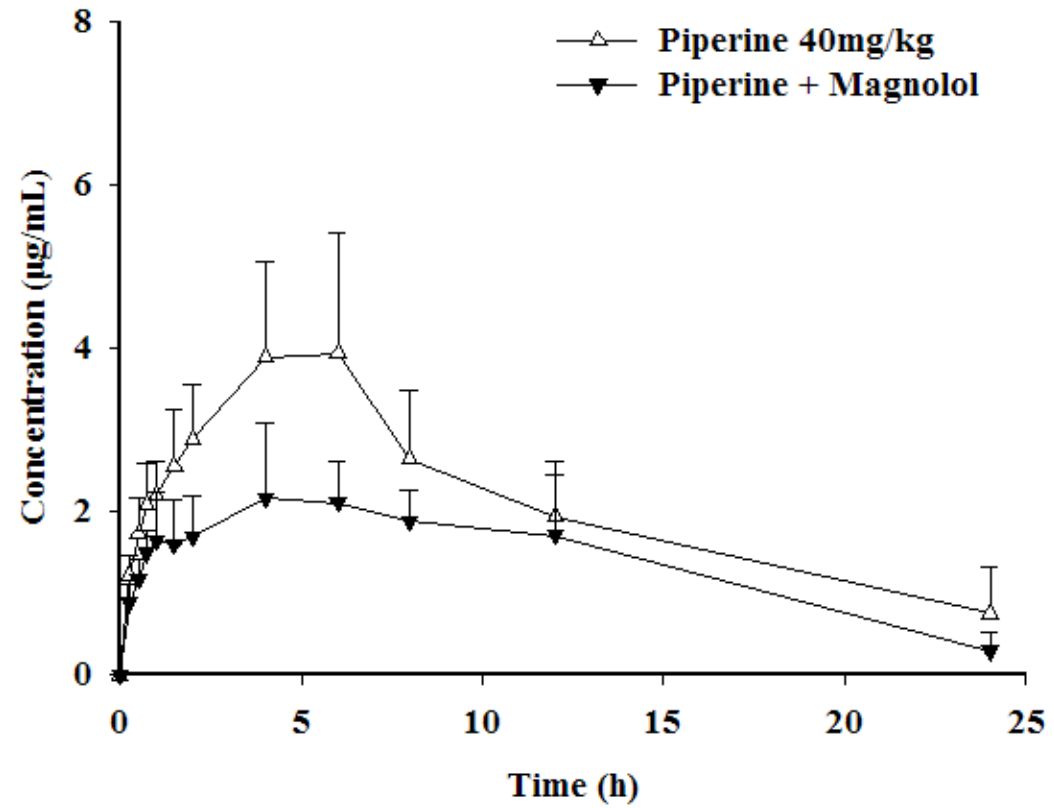

Figure 5: Plasma concentration-time profiles of piperine after oral administration of $40 \mathrm{mg} / \mathrm{kg}$ of piperine to rats in the presence and absence of magnolol. The data are expressed as mean $\pm \mathrm{SD},(n=6)$. ( $\boldsymbol{\nabla})$ piperine with $\mathrm{CMC}$; $(\Delta)$ piperine combined with magnolol 
Table 2: Pharmacokinetic parameters of piperine after oral administration of piperine 20 and $40 \mathrm{mg} / \mathrm{kg}$ to rats in the presence and absence of $625 \mathrm{mg} / \mathrm{kg}$ magnolol (mean $\pm \mathrm{SD}, n=6$ )

\begin{tabular}{lcccc}
\hline Parameter & \multicolumn{2}{c}{$\begin{array}{c}\text { Piperine } \mathbf{( 2 0} \mathbf{~ m g} / \mathbf{k g}) \\
\mathbf{+} \text { Magnolol }\end{array}$} & \multicolumn{2}{c}{ Piperine $\mathbf{4 0} \mathbf{~ m g} / \mathbf{k g})$} \\
& Alone & $\mathbf{+}$ magnolol \\
\hline $\mathrm{AUC}_{0-\mathrm{t}}\left(\mu \mathrm{g} / \mathrm{mL}^{*} \mathrm{~h}\right)$ & $14.66 \pm 5.91$ & $17.53 \pm 6.018$ & $44.89 \pm 17.87$ & $30.11 \pm 10.18$ \\
$\mathrm{AUC}_{0-\infty}\left(\mu \mathrm{g} / \mathrm{mL}^{*} \mathrm{~h}\right)$ & $14.66 \pm 5.91$ & $21.19 \pm 7.71$ & $50.56 \pm 21.63$ & $36.42 \pm 7.52$ \\
$C_{\max }(\mu \mathrm{g} / \mathrm{mL})$ & $1.79 \pm 0.22$ & $1.60 \pm 0.62$ & $4.30 \pm 1.47$ & $2.50 \pm 0.78^{*}$ \\
$T_{\max }(\mathrm{h})$ & $2.42 \pm 1.28$ & $2.70 \pm 1.20$ & $5.00 \pm 1.10$ & $6.00 \pm 3.10$ \\
$V_{\mathrm{d}}(\mathrm{L} / \mathrm{kg})$ & $3.37 \pm 1.48$ & $14.88 \pm 8.95$ & $7.23 \pm 1.79$ & $7.77 \pm 2.50$ \\
$C L(\mathrm{~L} / \mathrm{h} / \mathrm{kg})$ & $1.53 \pm 0.51$ & $1.04 \pm 0.34$ & $0.98 \pm 0.55$ & $1.14 \pm 0.23$ \\
$t_{1 / 2}(\mathrm{~h})$ & $1.80 \pm 0.17$ & $1.92 \pm 1.53$ & $7.08 \pm 2.44$ & $6.16 \pm 3.23$ \\
\hline
\end{tabular}

Note: Asterisks represent significant differences: ${ }^{*} p<0.05$ versus control group given piperine alone

\section{DISCUSSION}

P-glycoprotein (P-gp) as the drug export pump, is important for the absorption, distribution and excretion of drug $[11,12]$. Owing to various health promoting effects, dietary supplements as alternative medicines are becoming increasingly popular, leading to an increased incidence of patients taking the prescribed medicine with dietary supplements. Furthermore, given that many of the dietary supplements and phytochemicals can modulate the activity of P-gp and drug metabolizing enzymes, there should be more attention given to potential drug interactions with dietary supplements. Among dietary products, black pepper and long pepper are one of the most common culinary spices and nutrient enhancers. Piperine, a major active component of black pepper and long pepper, has been reported to enhance drug bioavailability and interactions by altering the pharmacokinetics [13]. In view of popular use of magnolol and piperine for the promotion of digestive function in dietaries and medicines, their concomitant intake should be paid attention to. In the present study, possible pharmacokinetic interaction was comparatively investigated following the concurrent administration of magnolol and piperine to rats.

Studies have shown that piperine inhibited P-gpmediated drug efflux during intestinal absorption to increase the plasma concentrations of some drugs, such as theophylline, phenytoin and refampin [14]. However, the results in the present study were opposite. As shown in Table 1, the $\mathrm{C}_{\max }$ and $\mathrm{AUC}_{0-\infty}$ were markedly decreased by co-administration of piperine at dosages of 20 and $40 \mathrm{mg} / \mathrm{kg}$, indicating that the oral bioavailability of magnolol in rats was significantly reduced by concurrent intake of piperine. Pharmacokinetic study of magnolol revealed that the absorption of magnolol was apparently hampered by piperine, of which both dosages of piperine exerted comparable effects. There was no significant difference between the two treatment groups (20 and $40 \mathrm{mg} / \mathrm{mL}$ ), implying that the interaction effect was not dosedependent.

Co-administration of high dose of piperine (40 $\mathrm{mg} / \mathrm{kg}$ ) with magnolol significantly decreased the plasma levels of piperine in the absorption phase and the $C_{\max }$. Although the AUC was reduced at $40 \mathrm{mg} / \mathrm{kg}$ piperine group, the difference was not statistically significant. Compared to the low dose piperine group, magnolol reduced the $\mathrm{C}_{\max }$ and delayed the $T_{\max }$ of piperine. However, the difference was not statistically significant $(p>$ 0.05). These results may be associated with the effect of magnolol on liver microsomal CYP450. It has been reported that magnolol exert significant inhibitory effects on the activities of CYP1A2 and CYP2E1 and relatively less effect on CYP3A4 [15]. In addition, our studies have found that magnolol did not affect the $T_{\max }$ value of piperine. These observations imply that magnolol might have little effect on the peristalsis of the gastrointestinal tract or gastric emptying time. However, the exact mechanisms underlying this effect still remain to be elucidated.

\section{CONCLUSION}

Co-administration of magnolol and piperine decreases the plasma concentration of either drug in rats. The findings suggest that concurrent use of magnolol and piperine or piperinecontaining diet requires close monitoring for potential interactions.

\section{ACKNOWLEDGEMENT}

This work was supported by grants from Hongkong, Macao and Taiwan Science \& Technology Cooperation Program of China (no. 2014DFH30010), Guangdong International Cooperation Project (no. 2013508102016), Science and Technology Planning Project of Guangdong Province, China (no. 2013B090600007, 2013B090600026 and 2012B090600007), and Guangdong Province 
Universities and Colleges Pearl River Scholar Funded Scheme (2011).

\section{REFERENCES}

1. Liu JQ, Tian JN, Zhang JY, Hu ZD, Chen XG. Interaction of magnolol with bovine serum albumin: a fluorescencequenching study. Anal Bioanal Chem 2003; 376(6): 864867.

2. Lin SP, Hou YC, Liao TY, Tsai SY. Enhancing the bioavailability of magnolol in rabbits using melting solid dispersion with polyvinylpyrrolidone, Drug Dev Ind Pharm 2014; 40(3): 330-337.

3. Sheng $Y L, X u J H$, Shi CH, Li W. Xu HY, Li N, Zhao YQ, Zhang XR. UPLC-MS/MS-ESI assay for simultaneous determination of magnolol and honokiol in rat plasma: Application to pharmacokinetic study after administration emulsion of the isomer, J Ethnopharmacolo 2014; 155(3): 1568-1574.

4. Wu AG, Zeng B, Huang MQ, Li SM, Chen JN, Lai XP. The absorption and transport of magnolol in Caco-2 cell model. Chin J Integr Med, 2013, 19: 206-211.

5. Lin CF, Hwang, T.-L., Al Suwayeh SA., Huang YL, Hung $Y Y$, Fang JY. Maximizing dermal targeting and minimizing transdermal penetration by magnolol/honokiol methoxylation. Int J Pharm 2013; 445(1-2): 153-162.

6. Kim RB, Fromm MF, Wandel $C$, Leake B, Wood A, Roden DM, Wilkinson, GR. The drug transporter $P$ glycoprotein limits oral absorption and brain entry of HIV-1 protease inhibitors. J Clin Invest 1998; 101(2): 289-294.

7. Hu Z, Yang X, Ho PCL, Chan SY, Heng PWS, Chan, E, Duan W, Koh HL, Zhou SF. Herb-drug interactions - A literature review. Drugs 2005; 65 (9): 1239-1282.
8. Bayne K. Revised Guide for the Care and Use of Laboratory Animals available. American Physiological Society. Physiologist 1996; 39 (4): 208-211.

9. Liang $Y Z$, Chen HM, Su ZQ, Hou SZ, Che $X Y$, Zheng $Y F$, $L i Y C$, Lin J, Z YX, Su ZR, et al. White pepper and piperine have different effects on pharmacokinetics of puerarin in rats. Evid-Based Compl Alt 2014; 2014:2014.

10. Wan RZ, Xu YY, Lin YP, Zhou MJ, Chang XL. Enhancing effects of different dosages of borneol on pharmacokinetics of salvanic acid $B$ after oral administration to rats. J Asian Nat Prod Res 2012; 14 (6): 538-544.

11. Jaszewska $E$, Kosmider $A$, Kis $A$, Naruszewicz $M$. Oenothera paradoxa defatted seeds extract containing pentagalloyl glucose and procyanidins potentiates the cytotoxicity of vincristine. J Physiol Pharmacol 2010; 61(5): 637-643.

12. Toklu H, Kabasakal L, Imeryuz N, Kan B, Celike C, Cetinel S, Orun O, Yuksel M, Dulger GA. A study comparing the efficacy of antimicrobial agents versus enzyme (P-gp) inducers in the treatment of 2, 4, 6 trinitrobenzenesulfonic acid-induced colitis in rats. $J$ Physiol Pharmacol 2013; 64(4): 439-451.

13. Balayssac D, Authier N, Cayre A, Coudore F. Does inhibition of P-glycoprotein lead to drug-drug interactions? Toxicol Lett 2005; 156(3): 319-329.

14. Jin MJ, Han HK. Effect of piperine, a major component of black pepper, on the intestinal absorption of fexofenadine and its implication on food-drug interaction. J Food Sci 2010; 75(3): 93-96.

15. Duan J, Xiao J, Chen Y, Han FM. Inhibition of Magnolol and honokiol on cytochrome $P 450$ enzymes in rat and human liver microsomes. Chinese Herb Med 2015; 7(2): 167-172. 